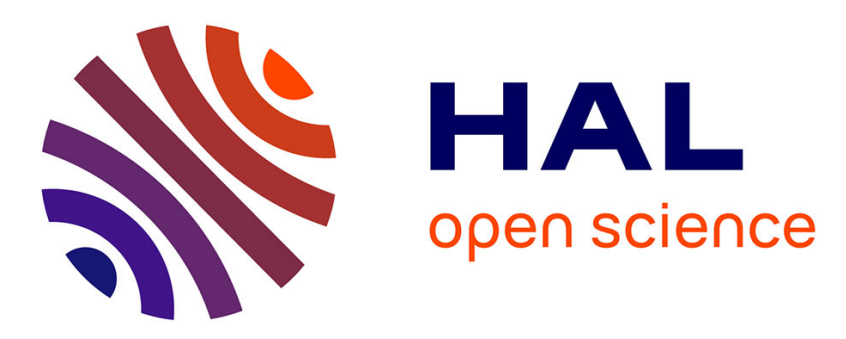

\title{
The study of defects in type-IV semiconductors by Mössbauer spectroscopy
}

M. van Rossum, G. Langouche, J. de Bruyn, M. de Potter, R. Coussement

\section{To cite this version:}

M. van Rossum, G. Langouche, J. de Bruyn, M. de Potter, R. Coussement. The study of defects in type-IV semiconductors by Mössbauer spectroscopy. Revue de Physique Appliquée, 1980, 15 (2), pp.311-322. 10.1051/rphysap:01980001502031100 . jpa-00244731

\section{HAL Id: jpa-00244731 https://hal.science/jpa-00244731}

Submitted on 1 Jan 1980

HAL is a multi-disciplinary open access archive for the deposit and dissemination of scientific research documents, whether they are published or not. The documents may come from teaching and research institutions in France or abroad, or from public or private research centers.
L'archive ouverte pluridisciplinaire HAL, est destinée au dépôt et à la diffusion de documents scientifiques de niveau recherche, publiés ou non, émanant des établissements d'enseignement et de recherche français ou étrangers, des laboratoires publics ou privés. 


\title{
The study of defects in type-IV semiconductors by Mössbauer spectroscopy (*)
}

\author{
M. van Rossum, G. Langouche, J. de Bruyn, M. de Potter and R. Coussement \\ Instituut voor Kern- en Stralingsfysika, Leuven University, B-3030 Leuven, Belgique
}

\begin{abstract}
Résumé. - L'article discute l'apport de la spectroscopie Mössbauer à l'étude des défauts dans les semiconducteurs. A titre d'illustration, nous présentons quelques résultats expérimentaux sur l'implantation de centres profonds dans $\mathrm{Si}, \mathrm{Ge}$ et diamant.
\end{abstract}

Abstract. - The paper discusses the use of Mössbauer Spectroscopy for the study of defects in semiconductors. Some recent experiments are presented which involve the implantation of deep centers in $\mathrm{Si}, \mathrm{Ge}$ and diamond.

In spite of the impressive amount of work and the many techniques devoted to the study of defects in semiconductors, it is clear at this moment that we do not have more than a fragmentary picture of these very complex phenomena.

In many cases, significant progress has been gained in our physical insight by concentrating various experimental methods on the study of a specific topic. In this paper, we want to discuss the contribution that Mössbauer spectroscopy can make in this field. As compared with other microscopic methods, Mössbauer spectroscopy is found to provide a very high density of information, which however may be difficult to extract in an unambiguous way. On the other hand, it is characterized by some short-sightedness which is typical for all nuclear techniques based on hyperfine interactions. Therefore, the choice of the appropriated probe nucleus is of utmost importance.

Part 1 reviews some generalities about Mössbauer effect (ME) and hyperfine interactions. Part 2 discusses the applications of ME to the study of radiation damage. In part 3 , this will be illustrated by some recent experiments which, to our opinion, have established Mössbauer spectroscopy in the field of semiconductor defects.

1. Mössbauer Spectroscopy. - 1.1 THE MossBAUER RESONANCE. - It is well known that nuclear resonance fluorescence of gamma rays is not possible in general. When a nuclear decay occurs from an excited state $E_{\mathrm{e}}$ to the ground state, the desexcitation energy of the nucleus will be divided between the energy of the gamma ray $E_{\gamma}$ and the recoil energy

$\left.{ }^{*}\right)$ Conférence présentée au Congrès de la Société Française de Physique (Toulouse).
$E_{\gamma} / 2 m c^{2}$ of the nucleus, where $m$ is the nuclear mass. The same partition occurs when a gamma-ray is absorbed by a nucleus. Therefore, the emitted gamma ray does not have enough energy to excite a stable nucleus from the ground state into the corresponding excited state $E_{\mathrm{e}}$, since it misses an amount $2 E_{\gamma} / 2 m c^{2}$. Moreover, $E_{\gamma}$ will be affected by the thermal motion of the free nucleus, which causes a Doppler broadening of the energy distribution.

It has been discovered by R. L. Mössbauer (1958) that emission and absorption of gamma rays can occur without recoil when the nuclei are embedded in a crystal lattice. In this case, the nuclear recoil energy may be too low to excite the lowest vibrational mode of the crystal, and the recoil is then taken up by the crystal as a whole, with negligible energy $E_{\gamma} / 2 M c^{2}, M$ being now the total mass of the crystal. The gamma ray energy $E_{\gamma}$ will then carry the full desexcitation energy $E_{\mathrm{e}}$, and the energy distribution will be determined by the natural width of the nuclear levels, since the Doppler broadening is almost eliminated by the elastic crystal forces. It follows that the emitted gamma ray can now be resonantly absorbed.

The linewidth is related to the mean lifetime $\tau$ of the level by the relation $\Gamma=\hbar / \tau$; for $\tau$ in the nanosecond range, this gives an energy resolution of about $10^{-7} \mathrm{eV}$ to $10^{-8} \mathrm{eV}$.

Since the decay probability of the nuclear level follows an exponential law, the cross-section of the resonance will show a Lorentzian lineshape :

$$
\sigma(E) \propto \frac{1}{\left(E-E_{0}\right)^{2}+\frac{\Gamma^{2}}{4}}
$$

where $E_{0}$ is the mean energy of the level. 
Because two resonant cross-sections are involved in the Mössbauer process (one for the emitter and one for the absorber), the experimental lineshape will be given by the convolution of the two resonant cross-sections, taking into account the exponential $\gamma$-absorption law in the absorber :

$$
I(E) \propto \int_{-\infty}^{+\infty} \sigma_{\mathrm{e}}\left(E-E^{\prime}\right) \exp \left[-a \sigma_{\mathrm{a}}\left(E^{\prime}\right)\right] \mathrm{d} E^{\prime} .
$$

For thin absorbers, this is still a Lorentzian with linewidth $2 \Gamma$.

1.2 The ReCOILless FRACTION. - The probability that a nuclear transition will not create phonons is given by the recoilless fraction or f-factor of the transition. If one assumes a Debye model for crystal lattice vibrations, $f$ is given by :

$f(T)=\exp \left[-\frac{3}{2} \frac{E_{\mathrm{R}}}{k_{\mathrm{B}} \theta_{\mathrm{D}}}\left\{1+4\left(\frac{T}{\theta_{\mathrm{D}}}\right)^{2} \int_{0}^{\theta_{\mathrm{D}} / T} \frac{x \mathrm{~d} x}{\mathrm{e}^{x}-1}\right\}\right]$

were $\theta_{\mathrm{D}}$ is the Debye temperature of the lattice, $E_{\mathrm{R}}$ the recoil energy of the nucleus and $T$ the absolute temperature of the lattice.

For low $T, f(T)$ may be approximated as :

$f(T) \cong \exp \left[-\frac{3}{2} \frac{E_{\mathrm{R}}}{k_{\mathrm{B}} \theta_{\mathrm{D}}}\left\{1+\frac{2}{3}\left(\frac{\pi T}{\theta_{\mathrm{D}}}\right)^{2}\right\}\right] \quad \frac{\theta_{\mathrm{D}}}{T} \gg 1$.

If the Mössbauer atoms occupy inequivalent sites in the lattice, they will have different recoilless fractions. Generally, their resonances will also be separated in energy (see 1.4.1). The area $\int_{-\infty}^{+\infty} I(E) \mathrm{d} E$ of each peak will depend on the recoilless fraction and on the fractional number of emitting nuclei which contribute to this specific resonance.

Since $f$ depends on $E_{\mathrm{R}}$ in an exponential way, it is clear that only low-energy gamma transitions $\left(E_{\gamma}<150 \mathrm{keV}\right)$ have a good probability to show up Mössbauer effect; moreover, the nuclear mass may not be too low $(A>50)$. This explains why only a limited number of nuclides are available for Mössbauer Spectroscopy.

1.3 EXPERIMENTAL SET-UP. - In order to scan the shape of the Mössbauer resonance, one has to change somehow the mean energy of the $\gamma$-rays. This can be reached by moving emitter and absorber relative to each other, which will cause a Doppler shift of the radiation energy by $\frac{v}{c} E_{\gamma}$, were $v$ is the relative velocity.

The Mössbauer spectrum is thus a record of the transmission of resonant gamma-rays through an absorber as a function of the relative velocity between source and absorber : the plot displays a number of counts versus energy. Both source or absorber may be moved, but for practical convenience one usually works with moving sources.

The spectrum is recorded on a repetitive basis, and the velocity transducer cyclically scans the whole velocity range of interest, at a frequency which may typically lay between 5 and $50 \mathrm{~Hz}$. Since the required velocities are usually of the order of $\mathrm{mm} / \mathrm{s}$ or $\mathrm{cm} / \mathrm{s}$, they can be produced by simple electromechanical set-ups similar to loudspeaker transducers.

The transmitted gamma-rays are counted by a conventional radiation detector, which may be a scintillation counter, a gas proportional counter or a semiconductor detector. Special electronic devices are needed for data acquisition. Since radiation has to be counted in a statistical way, the velocity change cannot be followed continuously, as would be the case for the record of analog information. Each velocity sweep is divided into some hundreds of blocks, corresponding with a few microseconds of counting time. The number of counts is then correlated with the mean velocity corresponding to the observation time interval, and this information is stored instantaneously in a multichannel analyzer, which allows permanent monitoring of the spectrum acquisition.

Except for a few cases (such as ${ }^{57} \mathrm{Fe}$ and ${ }^{119} \mathrm{Sn}$ ) the Mössbauer resonance cannot be observed at room temperature because of insufficient $f$. A cryostat should therefore be used, such that source and absorber can be cooled to liquid nitrogen or liquid helium temperature.

1.4 HYPERFINE INTERACTIONS. - Because of the very high resolving power of Mössbauer spectroscopy, it is possible to detect the influence of the electromagnetic interaction between the nucleus and the surrounding electrons on the nuclear levels. The perturbations of the nuclear energy induced by these interactions are usually of the same order of magnitude as the linewidth of the Mössbauer resonance. We will discuss now the most relevant aspects of the hyperfine interactions.

1.4.1 The isomer shift. - The electrostatic Coulomb interaction between the nuclear charge distribution and the electronic density inside the nucleus will shift the nuclear energy levels by an amount proportional to the size of the nucleus for that particular level. Two levels with different nuclear radii will therefore experience a change $S$ in their mutual separation, as compared to the unperturbed case :

$$
S=C \frac{\Delta R}{R} \rho(0)
$$

where $\Delta R / R$ is the relative difference in nuclear radius and $\rho(0)$ the electronic density in the nucleus (mainly due to $s$-electrons).

For two identical nuclei embedded in different materials, $\rho(0)$ will generally be different and also $S$. 
If one material contains a Mössbauer emitter and the other one the corresponding absorber, the Mössbauer resonance will be shifted away from zero velocity by an amount

$$
\left.\delta=S_{\mathrm{e}}-S_{\mathrm{a}}=C \frac{\Delta R}{R} \underset{\mathrm{z}}{\left(\rho_{\mathrm{e}}(0)\right.}-\rho_{\mathrm{a}}(0)\right)
$$

equal to the energy difference between the gamma transition in the source and in the absorber. This quantity is called the isomer shift. One of the possible numerical formulae is :

$$
\delta=\frac{4 \pi}{5} \frac{c \mathrm{Z}}{E_{\gamma}} e^{2} R^{2} \frac{\Delta R}{R}\left\{|\Psi(0)|_{\mathrm{e}}^{2}-|\Psi(0)|_{\mathrm{a}}^{2}\right\} .
$$

If the source does contain nuclei in different environments, each characterized by a specific $\rho(0)$, then a resonance should appear for each $\rho(0)$. The intensity of each line will of course depend on the population of that particular site and on its $f$-factor (cf. 1.2).
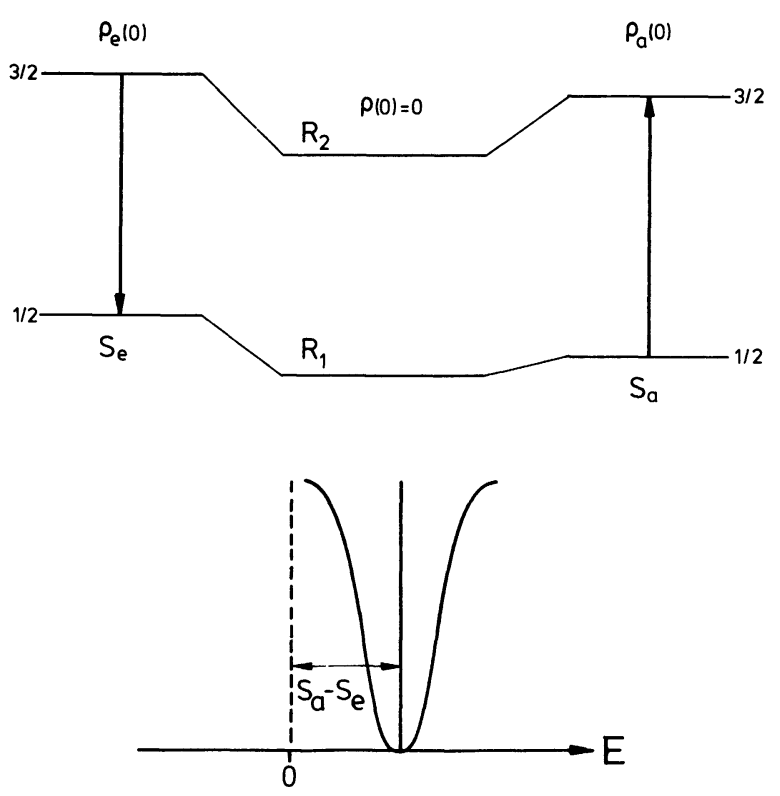

Fig. 1. - Isomer shift of the Mössbauer resonance.

It should be emphasized that $\delta$ involves the product of two unknown quantities $\mathrm{nl} .(\Delta R / R)$ and $\Delta \rho$. Therefore, deriving electronic configurations from isomer shift data is only possible if an independent determination of $\Delta R / R$ is available. This is not often the case, and so one will generally rely on semiquantitative arguments f.i. comparing the measured $\delta$ with some chemical compounds where the bond structure is rather well known.

1.4.2 The Zeeman splitting. - When a magnetic field is applied to the nucleus, it introduces a preferred orientation in space which totally lifts the degeneracy of the nuclear m-states. A state with spin I will be split in $2 I+1$ substates, according to the formula

$$
E_{\mathrm{m}}=-g_{\mathrm{I}} \mu_{\mathrm{N}} m_{\mathrm{I}} H
$$

$g_{\mathrm{I}}$ is the nuclear $g$-factor for that particular level, $\mu_{\mathrm{N}}$ the nuclear magneton and $H$ the applied field. Let us now consider a Mössbauer state decaying to the ground state. In principle, gamma-transitions are possible from any sublevel of the excited state to any sublevel of the ground state, and vice versa. However, angular momentum selection rules will restrict the number of allowed transitions according to the multipolarity of the gamma and will also determine their intensity through the Clebsch-Gordan coefficients. Since every transition contributes one resonance to the Mössbauer spectrum, this results in a typical pattern as shown in figure 2 for ${ }^{57} \mathrm{Fe}$. It should be noticed that polarization effects might also influence the relative intensity of the Mössbauer lines.
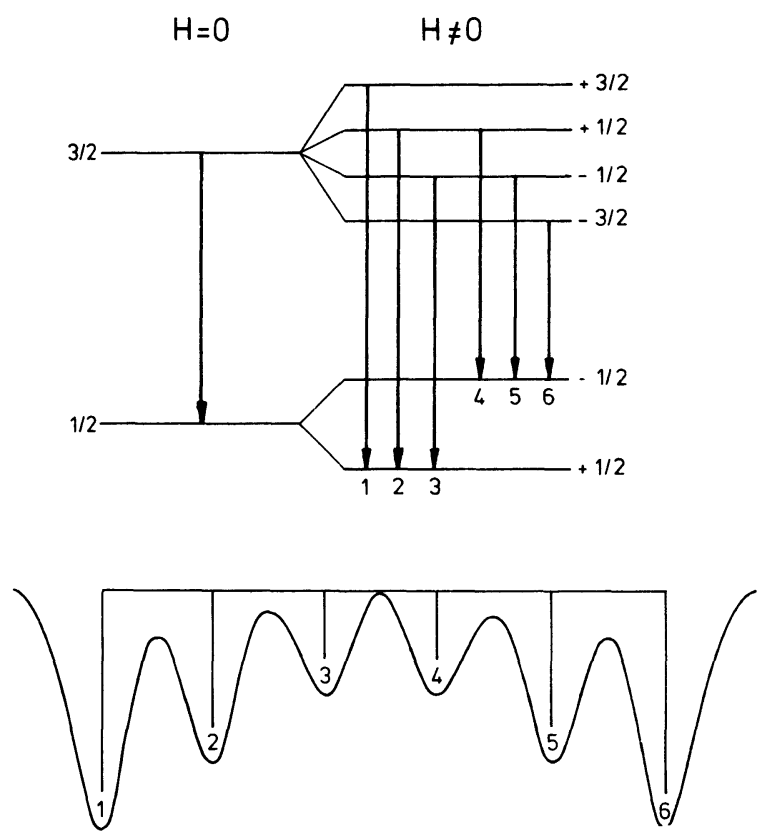

Fig. 2. - The Zeeman splitting.

1.4.3 The quadrupole interaction. - The isomer shift arises from the monopole term of the electronic charge distribution. The electric dipole term does not interact with the nucleus, since nuclei do not exhibit electrostatic dipole moments. However, if the nucleus is deformed it will show up a quadrupole moment, and this can interact with the quadrupole term of the electronic distribution. The general expression for this interaction is given by the tensorial product :

$$
H \propto \mathrm{e} \mathbf{Q} \times \mathbf{V}
$$

where $\mathbf{Q}$ is the nuclear quadrupole moment of the nucleus and $\mathbf{V}$ the electric field gradient of the electron distribution (EFG). 
It can be shown that the quantummechanical equivalent of this equation is given by :

$$
\hat{H}=\frac{e Q V_{\mathrm{zz}}}{4 I(2 I-1)}\left[3 \hat{I}_{\mathrm{z}}^{2}-\hat{I}^{2}+\eta\left(\hat{I}_{\mathrm{x}}^{2}-\hat{I}_{\mathrm{y}}^{2}\right)\right] .
$$

$\hat{I}\left(\hat{I}_{\mathrm{x}}, \hat{I}_{\mathrm{y}}, \hat{I}_{\mathrm{z}}\right)$ is the nuclear spin operator. $Q$ is the scalar nuclear quadrupole moment and $V_{z z}$ the z-component of the EFG, whereas

$$
\eta=\frac{V_{\mathrm{xx}}-V_{\mathrm{yy}}}{V_{\mathrm{zz}}}
$$

is called the asymmetry parameter of the EFG.

If $\eta=0$ (axially symmetric field gradient) the hamiltonian $\hat{H}$ commutes with $\hat{I}_{z}$ and the energy eigenvalues may simply be written as :

$$
E_{Q}=\frac{e Q V_{\mathrm{zz}}}{4 I(2 I-1)}\left[3 I_{\mathrm{z}}^{2}-I(I+1)\right] .
$$

Since the quadrupole interaction splits up the nuclear energy levels according to $\mathrm{m}^{2}$, it will also split the Mössbauer resonance into several satellite lines, corresponding with transitions between the sublevels of the ground state and excited Mössbauer state (Fig. 3). The number of lines will depend on the spin of the Mössbauer state and ground state. In ${ }^{57} \mathrm{Fe}$ f.i. the spin sequence is $\frac{3}{2} \rightarrow \frac{1}{2}$ and the resonance will be split into a doublet corresponding to the transitions $\left( \pm \frac{3}{2} \rightarrow \pm \frac{1}{2}\right)$ and $\left( \pm \frac{1}{2} \rightarrow \pm \frac{1}{2}\right)$; the relative intensity of the satellite lines will be determined by angular momentum selection rules and can also be affected by the orientation of the emitted $\gamma$-rays with respect to the field gradient axes.


Fig. 3. - The quadrupole splitting.
An external magnetic field can be applied to a sample already showing a quadrupole splitting. This results in a combined magnetic-quadrupole interaction, which sometimes proves useful to clarify the interpretation of the spectra.

In type IV semiconductors, the detection of a quadrupole interaction is of particular interest. Since the lattice has cubic symmetry, no field gradient exists in an undisturbed surrounding. The presence of a quadrupole interaction therefore indicates the existence of defects or distorted lattice positions.

\section{Study of radiation damage : general considera-} tions. - The ME is well suited for the investigation of microscopic defect structures, for Mössbauer spectra are able to display detailed pictures of the various sites occupied by Mössbauer atoms in a lattice. Different neighbourhoods will be distinguished by their charge or spin symmetry, their electronic density and by their influence on the vibrational behaviour of the Mössbauer atom. Under favorable conditions, each definite lattice site provides its specific component to the Mössbauer spectrum. Unfortunately, this does not always result in a clear physical insight. Indeed, too many lattice sites can make the Mössbauer spectrum difficult to analyze, especially when they differ only slightly from each other. Moreover, the reconstruction of the site starting from the Mössbauer parameters is not always straightforward, because of a lack of theoretical models. These are general limitations which one often encounters when practicing Mössbauer spectroscopy.

Because the Mössbauer probe does not sense more than a few lattice distances away from its own position, one has somehow to bring it in contact with the defect configurations to be studied. This can be done in two different ways, namely :

1) trapping of uncorrelated damage by the impurity

2) interaction of the impurity with correlated damage.

Both methods rely on the same basic idea. In order for Mössbauer atoms to be associated with defects, this association should result in an energetically favored configuration. If the size of the impurity is larger than the host interatomic spacing, an association with vacancies will allow the impurity to lower its potential energy. Similarly, small impurities are expected to stabilize their position by associating with host interstitials, if these are available in their immediate surrounding. A suitable choice of the Mössbauer impurity therefore allows to select a specific type of defects. This approach, how naive it may seem at first sight, has been proved to work well for the study of radiation damage in metals, where the defect structures are not too complicated. In semiconductors, the situation is much more complex and the type of defects encountered may depend crucially on the electronic properties of both host 
and impurity. Nevertheless, the simple picture described above may still be useful as a practical guideline for the investigators. We shall now try to explain how it works with a few typical examples.

2.1 INTERACTION WITH CORRELATED DEFECTS. By correlated "defect interaction we mean the interaction of an impurity with the defects created on its own damage track. As a matter of fact, this kind of correlation can only be observed with implanted atoms.

It is generally accepted that in metals most implanted impurities (provided they are not too small) land up at substitutional sites by a replacement collision. However, the vicinity of the landing site is heavily damaged so that a subsequent association of the impurity with vacancies or interstitials may occur in a very short time. The fraction of implanted atoms which according to the Mössbauer spectrum occupy substitutional positions (shortly called substitutional fraction) therefore varies from one case to the other, depending essentially on the size of the Mössbauer parent as compared to the size of the host atoms. Moreover, when the implanted dose is high enough to cause overlap of implantation tracks, the density of defects around the impurities increases, giving rise to dose dependence of the substitutional fraction.

Historically, this correlated defect production was the first one to be observed, when several groups tried to introduce Mössbauer nuclei into metallic hosts by direct or recoil implantation. Pioneering experiments on the implantation of ${ }^{129} \mathrm{Te}$ and ${ }^{133} \mathrm{Xe}$ in several bcc and fcc metals were performed between 1965 and 1969 by De Waard and Drentje in Groningen [2-5]. It was proved that the implanted impurities could be distributed over various sites, corresponding with a different number of associated vacancies. Starting from this work, more extensive studies were undertaken in this field, mainly in Groningen and Leuven. The Leuven group has especially

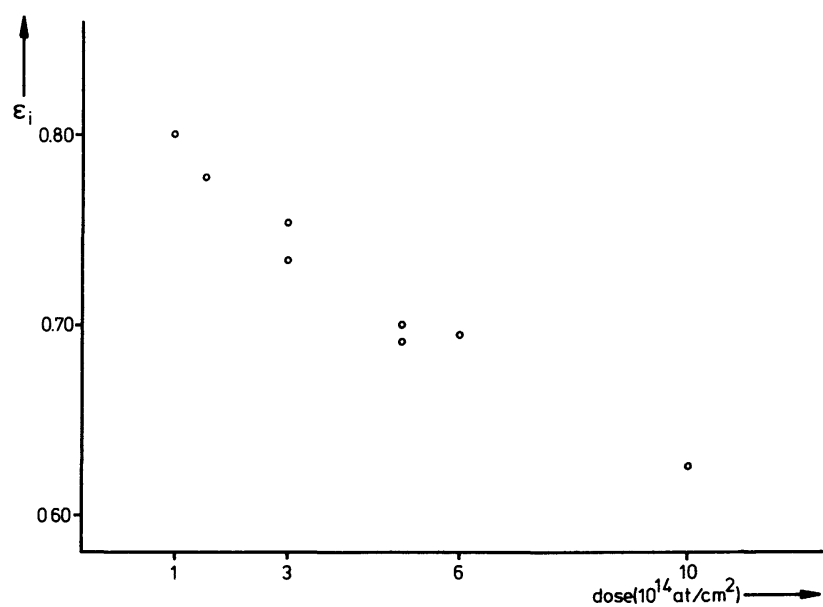

Fig. 4. - Dose dependence of the substitutional fraction of Xe in W, as determined by Mössbauer Spectroscopy. After Odeurs et al. [9]. concentrated on the study of the various factors which might influence the substitutional fraction, such as dose, dose rate and implantation temperature. A theoretical model was developed which could describe the influence of the various implantation parameters on the substitutional fraction in analytic form [6-7]. The dose dependence of the substitutional fraction was first demonstrated by ME with ${ }^{129 m} \mathrm{Xe}$ implanted in iron [8], but has been extended to other metals as well [9]. The importance of dose rate and temperature was illustrated with ${ }^{133} \mathrm{Xe}$ [10]. A comparison between Mössbauer and channeling results on the same samples has been published by De Waard and Feldman [11].

2.2 THE TRAPPING METHOD. - According to this technique, the Mössbauer probes are introduced into the lattice without creation of defects (f.i. by thermal diffusion or alloying). Subsequently, the sample is irradiated in order to produce point defects in an uncorrelated way. During their migration, these defects are trapped by impurity atoms, which results in a modification of the Mössbauer spectrum, indicating the diffusion of the defects. These experiments are especially interesting when performed as a function of temperature.

Some of the most beautiful applications of the trapping method, which also constitute a most valuable contribution of Mössbauer spectroscopy to the study of radiation damage, can be found in the experiments of Mansel and Vogl [12-15]. Dilute $\mathrm{AlCo}^{57}$ and $\mathrm{AgCo}^{57}$ alloys were irradiated at liquid helium temperature with fast neutrons or electrons. Then by gradually raising the temperature of the sample, interstitial defects were allowed to migrate and were trapped by Co impurities. This trapping occurred at annealing stage I and gave rise to a new Mössbauer line, corresponding with a Co-interstitial mixed dumbbell configuration. Combination of isomer shift and recoilless fraction measurement allowed to investigate the dynamical behaviour of this mixed dumbbell. At higher annealing temperatures, the detrapping of the interstitials could be observed. Whereas in AgCo interstitial release occurred at stage II, it could be proved that the interstitials trapped in AlCo were annihilated by freely migrating vacancies in stage III. These results have also been correlated with resistivity measurements on the same sample.

An interesting development of the implantation method towards the study of uncorrelated defects was also initiated in Groningen. By heating of the metal host at the appropriate temperature, one allows the implanted impurity to interact with defects migrating from other damage cascades. This has been done by Reintsema et al. [16] for vacancy migration and by Odeurs et al. [17] for interstitial migration.

All experiments mentioned above were source 
measurements i.e. the Mössbauer impurities were radioactive. It is also possible to work with stable impurities and perform absorber experiments; this technique has been developed in Cracow since 1973 with implanted ${ }^{57} \mathrm{Fe}[18]$. However, in this case the concentration of impurities in the lattice has to be very large, because of the small capture cross-section for resonant gamma rays. The samples therefore look more like intermetallic alloys, and the type of problems encountered are of a rather different nature.

3. Applications to semiconductors. - We will now proceed to the review of some results obtained in the field of semiconductors. Since the potentialities of Mössbauer spectroscopy depend very much on the isotope that has been chosen for the investigation, we have classified the various papers according to the Mössbauer nuclei. It turns out that each nucleus has its own problematics which determines the course of the experimental work.

Since the Mössbauer levels are short-lived (nanoseconds or less), they have to be fed by some parent activity. Sometimes, this is an isomeric state of the Mössbauer nucleus itself (f.i. ${ }^{119 \mathrm{~m} S n},{ }^{125 \mathrm{~m}} \mathrm{Te},{ }^{129 \mathrm{~m}} \mathrm{Xe}$ ). Alternatively, the parent nucleus may belong to another element and decay to the Mössbauer level by weak interaction $\left({ }^{57} \mathrm{Co} \rightarrow{ }^{57} \mathrm{Fe}, \quad{ }^{129} \mathrm{Te} \rightarrow{ }^{129} \mathrm{I}\right.$, $\left.{ }^{133} \mathrm{Xe} \rightarrow{ }^{133} \mathrm{Cs}\right)$. In this case, one might ask oneself which element is really studied. It turns out experimentally that the implantation behaviour of the impurity is generally determined by the parent element, whereas the chemical properties belong to the daughter. There may of course be exceptions to this rule.

In some hosts (mostly isolators) the $\beta$-decay itself may cause some perturbation in the Mössbauer spectrum (decay after-effects). However, such phenomena have not been observed in semiconductors up to now.

3.1 MösSBAUER SPECTROSCOPY ON ${ }^{119} \mathrm{Sn}$. - 3.1.1 Lattice location of $\mathrm{Sn}, \mathrm{Sb}$ and $\mathrm{Te} .-{ }^{119} \mathrm{Sn}$ is the only known Mössbauer nucleus corresponding with an isoelectronic impurity in type-IV semiconductors. Moreover, the Mössbauer level can be fed from the radioactive decay of ${ }^{119 \mathrm{~m}} \mathrm{Sn},{ }^{119} \mathrm{Sb}$ and ${ }^{119} \mathrm{Te}$. This means that one can study the implantation behaviour of an isoelectronic impurity ( $\mathrm{Sn})$, a single donor ( $\mathrm{Sb}$ ) and a deep impurity (Te) using the same $\gamma$-transition. These facts, together with the relative easiness of ${ }^{119} \mathrm{Sn}$ spectroscopy, makes the use of this nucleus as a probe especially attractive.

A thorough study on this subject is due to G. Weyer et al. [19-23]. ${ }^{119 \mathrm{~m}} \mathrm{Sn},{ }^{119} \mathrm{Sb}$ and ${ }^{119 \mathrm{~m}} \mathrm{Te}$ were implanted in $\mathrm{Si}, \mathrm{Ge}$ and diamond, and also in $\alpha-\mathrm{Sn}$. Because the implanted doses exceeded $10^{14} \mathrm{at} / \mathrm{cm}^{2}$, implantations were performed at $400{ }^{\circ} \mathrm{C}$ in order to minimize the amorphization process. However, some room temperature implantations were also carried out, without important change in the spectra.

While $\mathrm{Sn}$ or $\mathrm{Sb}$ ended mainly on substitutional sites, Te was found to be distributed over substitutional, interstitial and damage sites. Moreover, evidence was found for a $\mathrm{Te}-\mathrm{O}$ association in silicon. Annealing sequences showed the Te damage structures to be very stable, while the same structures containing $\mathrm{Sb}$ annealed between $400^{\circ} \mathrm{C}$ and $600^{\circ} \mathrm{C}$. According to the authors, at least one of these defect structures corresponds with a vacancy-associated site.

Recoilless fractions of ${ }^{119} \mathrm{Sn}$ in $\mathrm{Si}, \mathrm{Ge}$ and diamond have been measured and compared with theoretical predictions. The isomer shifts of the ${ }^{119} \mathrm{Sn}$ resonance in $\mathrm{Si}, \mathrm{Ge}$, diamond and $\alpha-\mathrm{Sn}$ have been correlated in a theoretical model by Antoncik [24]. Starting from a covalent bond model of Lenglart and Lannoo, the author assumed the electron density at the $\mathrm{Sn}$ nucleus to be proportional to the difference in valence between the host and the Sn impurity.

Recently, the same authors have reported implantations of ${ }^{119 \mathrm{~m}} \mathrm{Sn}$ in GaAs. The dominant position seems to be the substitutional Ga site [25].

3.1.2 Study of radiation damage in $\mathrm{Si}$. - Evidence for tin-vacancy interactions in $\mathrm{Si}$ has been reported in 1974 by Matsui et al. [26]. ${ }^{119 m}$ Sn was diffused into p- and n-type $\mathrm{Si}$; these samples were irradiated with fast neutrons at $80 \mathrm{~K}$ up to a total dose of about $10^{18} \mathrm{n} / \mathrm{cm}^{2}$. In the p-type sample, the creation of vacancies manifested itself immediately by the appearance of a new line in the Mössbauer spectrum, which was attributed to a tin-vacancy association. In the n-type material, the spectrum changed only after annealing at $140^{\circ} \mathrm{C}$; the single line resonance was then replaced by a doublet.

This behaviour suggests that the tin-vacancy pairing in the p-type crystal occurs directly by irradiation, while it is retarded in the n-type crystal until the $P$-vacancy pair dissociates by annealing. The n-type doublet is described by [110] bond composed of $5 \mathrm{sp}$ orbitals. The p-type singlet is represented by [111] bond with enhanced $\mathrm{p}$-character compared to $s p^{3}$ bond.

3.2 Mössbauer Spectroscopy on ${ }^{129} \mathrm{I}$. -3.2 .1$ Lattice location of $\mathrm{Te}$. - The best way to reach the $27 \mathrm{keV}$ Mössbauer level in ${ }^{129} \mathrm{I}$ is to start from ${ }^{129 m} \mathrm{Te}$. Implantations of ${ }^{129 \mathrm{~m}} \mathrm{Te}$ in $\mathrm{Ge}, \mathrm{Si}$ and diamond have been reported by Hafemeister and de Waard [27]. The spectra showed two well resolved lines of equal intensity, with an isomer shift separation of about $3 \mathrm{~mm} / \mathrm{s}$ (Fig. 5). This is apparently in good agreement with channeling results, which show the Te atoms to be equally distributed between a substitutional and an undefined interstitial position. The Mössbauer spectrum by itself doesn't tell which resonance is related with the substitutional site. However, by comparing the position of both lines with isomer shifts of known chemical compounds, 


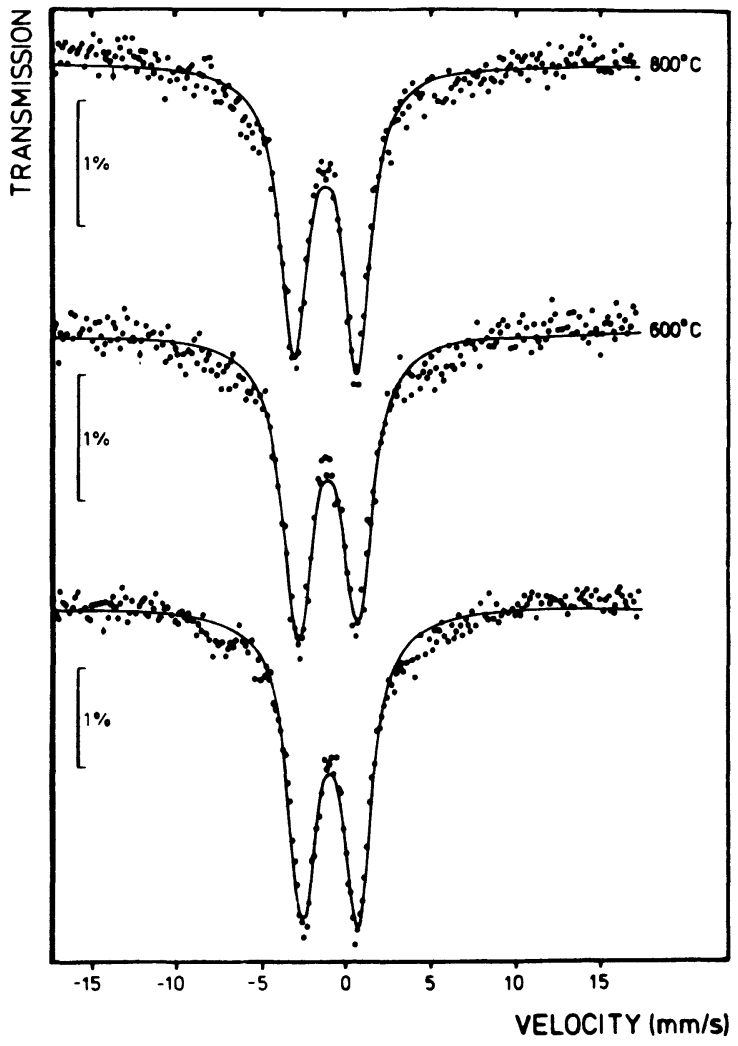

Fig. 5. - Spectra of ${ }^{129 \mathrm{~m}} \mathrm{Te}$ implanted in Si. The two upper spectra show thermal annealing steps. After De Bruyn et al. [29].

one of the peaks (the one at positive velocity) was found somewhat in the vicinity of the $\mathrm{sp}^{3}$ configuration, and was therefore attributed to the substitutional site. Moreover, a linear relation was established between the position of both resonances and the host lattice spacing. The same linear relation was even found to hold for ${ }^{129} \mathrm{Te}$ implanted in $\alpha$-Sn and $\mathrm{SiC}$ [28], which also have a diamond - type lattice structure. For the substitutional site, this behaviour was attributed to a covalency effect. For the interstitial site, corresponding with the peak at negative velocity, it was thought that a compression of the impurity by the surrounding host neighbours might increase the electronic density at the I nucleus linearly with interatomic distance decrease.

Although the authors have been looking for correlated radiation damage, no influence of the implanted dose could be seen between $10^{14}$ and $10^{17} \mathrm{at} / \mathrm{cm}^{2}$. Variation of the dose rate, implantation temperature or subsequent annealing temperature did not produce any significant change in the spectra. This may be considered as a proof that the observed sites are not connected with defect structures. It also turns out that in this particular case the Mössbauer effect is not sensitive to the recrystallization of the lattice.

3.2.2 Laser and thermal annealing of Te-implanted Si. - In order to get additional information on the behaviour of implanted $\mathrm{Te}$ in $\mathrm{Si}$, a comparative study of thermal and laser annealing on the implanted sample (dose $\cong 10^{14} \mathrm{at} / \mathrm{cm}^{2}$ ) has been performed by De Bruyn et al. [29]. Thermal annealing up to $800^{\circ} \mathrm{C}$ did not modify the spectrum shape, hereby confirming the stability of the implantation sites. However, a drastic change occurred after laser annealing (Fig. 6). After a first shot of $1.8 \mathrm{~J} / \mathrm{cm}^{2}$ (ruby laser pulse duration 20-30 ns), the intensity of the line at positive velocity diminished significantly, while the intensity of the other line increased. The next annealing step with a mean energy density of $2.7 \mathrm{~J} / \mathrm{cm}^{2}$ gave only a line broadening. By further increasing the energy density to $3.6 \mathrm{~J} / \mathrm{cm}^{2}$ a third line appeared at $0.22 \mathrm{~mm} / \mathrm{s}$ and the linewidth still broadened.

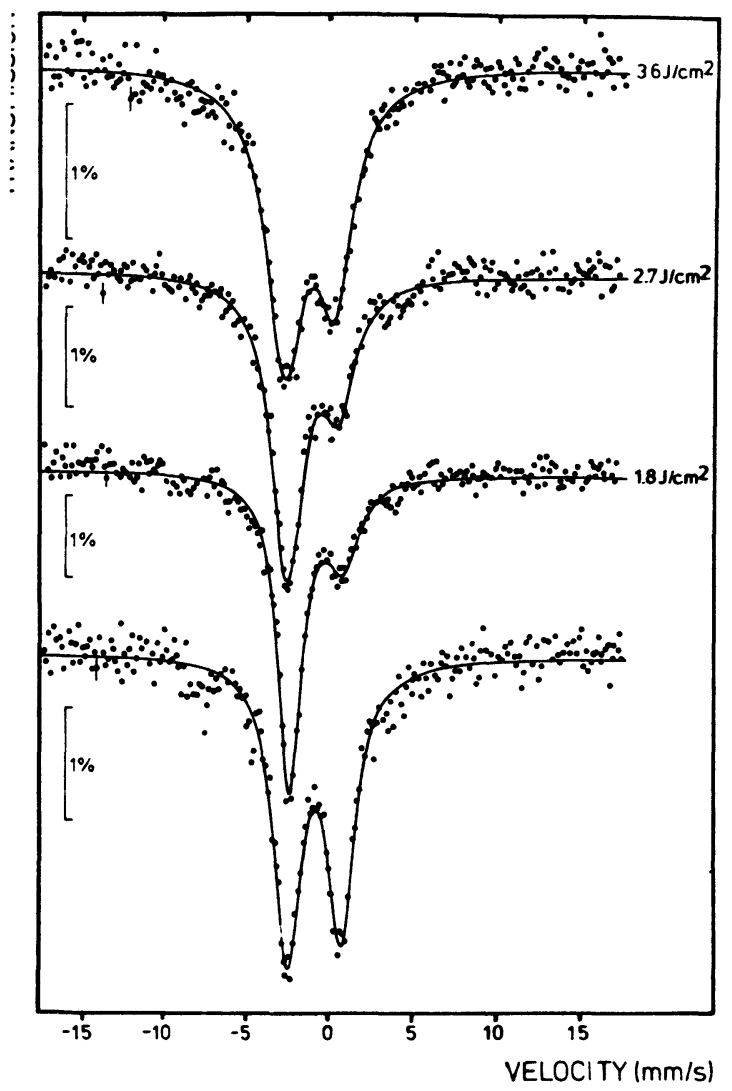

Fig. 6. - Laser annealing of ${ }^{129 \mathrm{~m}} \mathrm{Te}$ implanted in Si.

These observations should be compared with recent channeling measurements by Foti et al. on laser annealed TeSi [30]. They showed that up to $80 \%$ of the implanted $\overline{\mathrm{T} e}$ in Si are located in the substitutional position. According to this result, one should assign the line at negative velocity to the substitutional site. This is in contradiction with the previous interpretation where the peak at positive velocity, i.e. the lowest energy state was assumed to be the substitutional one. We thus conclude that the configuration of the substitutional I is too complex to be described by a simple $\mathrm{sp}^{3}$-like hybridized bond. 
After the reassignment of the sites, one sees that the interstitial site now corresponds to a low electronic density. This interpretation is compatible with recent calculations and experiments on the pressure dependence of the electron density at I [31]. It turns out from the calculations that compression of the I atom decreases the electron density at the nucleus, due to an enhanced shielding effect of the $p$ orbitals, which push the $s$-electrons out of the nuclear region.

After the highest energy annealing step, we notice that a third peak arises while the interstitial line has disappeared and the intensity of the substitutional line has decreased. According to Foti et al., high power irradiation modifies the impurity profile so that part of the Te atoms moves to the crystal surface. Therefore, the third component can be associated with $\mathrm{Te}$ atoms migrated to the surface of the sample.

3.3 MösSBaUER SPECTROSCOPY ON ${ }^{57} \mathrm{Fe} .-3.3 .1$ Lattice location of $\mathrm{Co}$ and $\mathrm{Fe}$. - Lattice locations of ${ }^{57} \mathrm{Co}$ and ${ }^{57} \mathrm{Fe}$ in type-IV semiconductors have been investigated from the very beginning of Mössbauer spectroscopy. From spectra of ${ }^{57} \mathrm{Co}$ (parent activity) diffused in $\mathrm{Si}$ and $\mathrm{Ge}$, Wertheim [32] deduced that $\mathrm{Co}$ essentially forms clusters in $\mathrm{Si}$ whereas in $\mathrm{Ge}$ it occupies an off-centre substitutional position, giving rise to a quadrupole interaction. The samples were also irradiated with electrons, without noticeable change in the spectra.

Implantation of ${ }^{57} \mathrm{Fe}$ was first performed in Stanford [33]. Stable ${ }^{57} \mathrm{Fe}$ was recoil-implanted in $\mathrm{Si}$, Ge and diamond, and simultaneously activated to the Mössbauer level by Coulomb excitation. In these experiments the implantation energy is very high $(20-30 \mathrm{MeV})$ and the dose very low $\left(\cong 10^{10} \mathrm{at} / \mathrm{cm}^{2}\right)$. The spectra showed two resonance lines of unequal intensity; the intensity ratio was found to depend on the host element and implantation temperature. The lines were interpreted as arising from interstitial and substitutional iron.

Low energy implantations $(60 \mathrm{keV})$ of ${ }^{57} \mathrm{Co}$ in diamond were performed by Barros et al. [34]; the implanted dose was about $10^{14} \mathrm{at} / \mathrm{cm}^{2}$. Two lines of equal magnitude were observed, which therefore were attributed to a quadrupole splitting of the ${ }^{57} \mathrm{Fe}$ Mössbauer level. The $\mathrm{Fe}$ was supposed to be in a disturbed interstitial position.

It should however be emphasized that there is no straightforward interpretation for a ${ }^{57} \mathrm{Fe}$ spectrum consisting of two equal lines. Since the $14 \mathrm{keV}$ Mössbauer level of ${ }^{57} \mathrm{Fe}$ has spin $3 / 2$, it splits up into two sublevels $( \pm 3 / 2, \pm 1 / 2)$ when subjected to an electric field gradient. A spectrum of two equal absorption peaks can therefore be interpreted as one quadrupole split component. However, it may equally well arise from two distinct lattice sites with a different electronic density. Much of the subsequent work was aimed to solve this fundamental ambiguity.
Low energy $(60 \mathrm{keV})$ implantations of ${ }^{57} \mathrm{Co}$ in $\mathrm{Si}$, $\mathrm{Ge}$ and diamond (also in $\alpha-\mathrm{Sn}$ ) have been reported by Weyer et al. [35]; the implanted dose was at least $10^{14} \mathrm{at} / \mathrm{cm}^{2}$. The spectra consisted of two broad, slightly asymmetric lines. From some fine structure of the resonances, it was assumed that both of them contained two nearly superimposed components, making four distinct sites in total. More recently, Weyer et al. [36] have compared samples of implanted and diffused ${ }^{57} \mathrm{Co}$ in Si. Nearly identical spectra were obtained for high temperature $\left(600^{\circ} \mathrm{C}\right)$ implanted samples and for diffused samples quenched from $1250^{\circ} \mathrm{C}$. Again, the spectra were decomposed into four different lines, which were attributed to substitutionally dissolved Co atoms and to metastable precipitates.

However, this analysis was disproved by Langouche et al. [37]. By applying an external magnetic field of $8 \mathrm{~T}$ on an implanted at $10^{14}$ at $/ \mathrm{cm}^{2}{ }^{57} \mathrm{CoSi}$ source, spectra were obtained which could be analyzed in an unambiguous way (Figs. 7-8). It was shown that the main part of the spectrum consisted of a quadrupole split component; in addition at least one single line was also present.

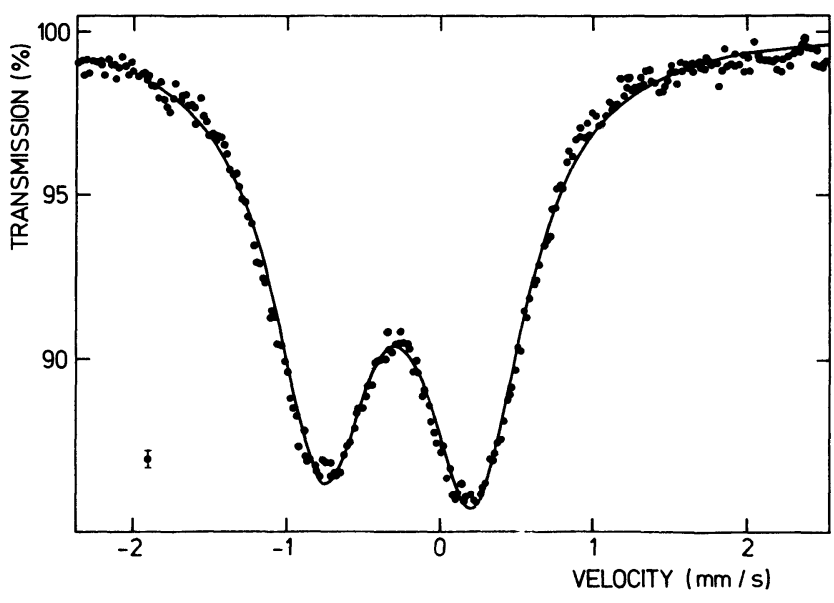

Fig. 7. - Spectrum of ${ }^{57} \mathrm{Co}$ implanted in $\mathrm{Si}$ at $10^{14} \mathrm{at} / \mathrm{cm}^{2}$.

3.3.2 Study of implantation damage. - Whereas experiments on ${ }^{119} \mathrm{Sn}$ and ${ }^{129} \mathrm{I}$ have been unable to show any substantial influence of the lattice amorphization on the spectrum, it has been proved by the Leuven group that ${ }^{57} \mathrm{Co}$ is very sensitive to the symmetry of its surrounding [38]. By an optimalization of the implantation technique, it has been possible to lower the total implanted dose below $10^{14} \mathrm{at} / \mathrm{cm}^{2}$. A drastic change occurs in the spectra of $\mathrm{CoSi}$ and CoGe between $10^{12}$ and $10^{14} \mathrm{at} / \mathrm{cm}^{2}$ (Fig. 9). $\overline{\mathrm{At}}$ low doses, a strong single line component near zero velocity is superimposed on the quadrupole doublet, which is no longer the main part of the spectrum. 


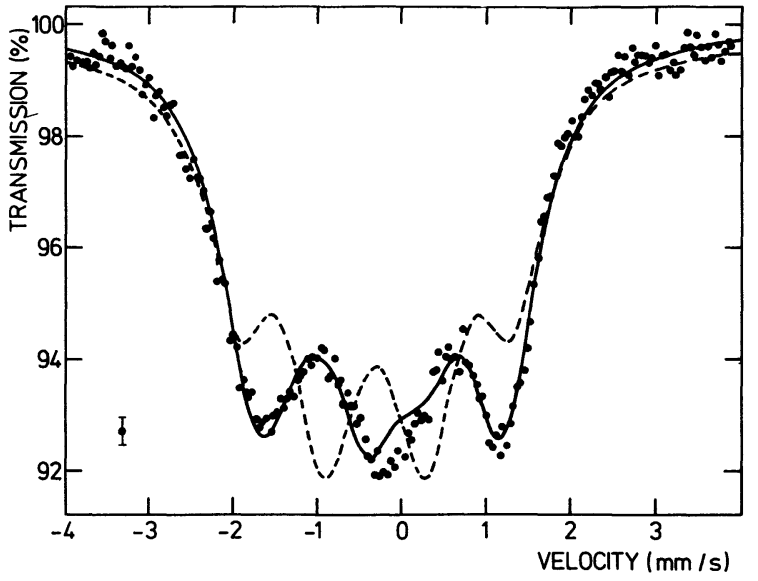

Fig. 8. - Same source as in figure 7, but with external magnetic field of $8 \mathrm{~T}$. The full line shows the best fit with a combined magneticquadrupole interaction. The dashed line shows the expected result for a Zeeman splitting of two independent resonances.

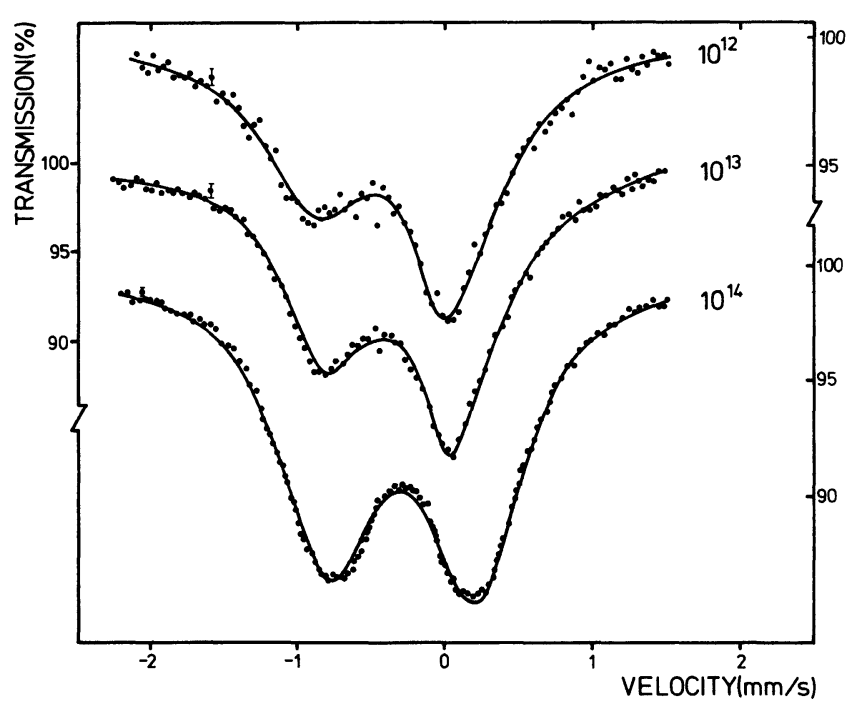

Fig. 9. $-{ }^{57} \mathrm{Co}$ implanted in $\mathrm{Si}$ at various doses.

From the dose dependence, it may be inferred that the quadrupole doublet belongs to the Co atoms that came to rest in the amorphous region of the crystal. The single line, on the other hand, belongs to the atoms that find themselves in an undamaged surrounding. Whether this is a segregated phase or a regular lattice site cannot be determined from the present measurements.

In order to check this interpretation, thermal annealing sequences were performed on ${ }^{57} \mathrm{CoSi}$ and ${ }^{57} \mathrm{CoGe}$ [39]. In $\mathrm{Si}$, the recovery of the crystalline lattice could be followed by the gradual disappearance of the quadrupole split component, which was replaced by another doublet with smaller splitting; at $900{ }^{\circ} \mathrm{C}$ this component is no longer visible. Some decrease in the intensity of the quadrupole doublet was also observed after thermal annealing of the Ge sample.

A similar decrease of the amorphization could be obtained when the sample was heated above room temperature during the implantation. At equal temperatures, there is a striking similarity between hot implants and post implantation annealed samples.

\subsubsection{Laser annealing of ${ }^{57} \mathrm{CoSi}$ and ${ }^{57} \mathrm{CoGe}$. -} Both a $Q$-switched ruby laser and neodymium glass laser were used to anneal ${ }^{57} \mathrm{CoSi}$ and ${ }^{57} \mathrm{CoGe}$ samples, implanted at $10^{14} \mathrm{at} / \mathrm{cm}^{2}$ [39]. A first observation is that the Nd laserpulse did not affect the Si sample, which might be due to the fact that the Nd laserlight just barely overlaps the Si bandgap. The other experiments showed a drastic change in the Mössbauer spectrum. In all cases the large quadrupole doublet, typical for the Co atoms in the amorphized layer, has been replaced by other components. The most surprizing result is that $\mathrm{Si}$ and Ge behave differently. A ruby laser flash on the $\mathrm{Si}$ sample replaces the large quadrupole splitting by a smaller one, as was also observed after thermal annealing to $400{ }^{\circ} \mathrm{C}$, just above the recrystallisation temperature. On the other hand, the Ge sample shows a Mössbauer spectrum with a very intense single line. Channeling measurements will be needed to explore the different lattice sites involved.

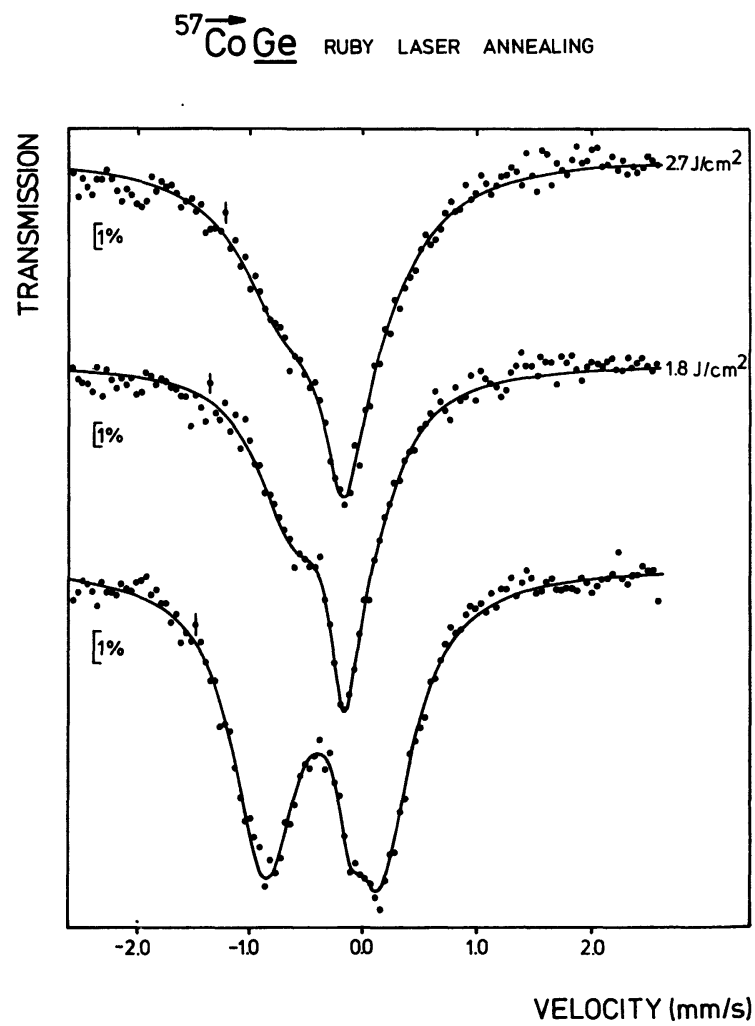

Fig. 10. - Ruby lasër annealing of ${ }^{57} \mathrm{CoGe}$. 
3.4 Mössbauer Spectroscopy ON ${ }^{129} \mathrm{Xe}$ AND ${ }^{133} \mathrm{Cs}$. - 3.4.1 Lattice location of $\mathrm{Xe}$ in $\mathrm{Si}$ and $\mathrm{Ge}$. In order to do Mössbauer spectroscopy on Xe implanted samples, one can implant ${ }^{129 m} \mathrm{Xe},{ }^{131 \mathrm{~m}} \mathrm{Xe}$ or ${ }^{133} \mathrm{Xe}$ (decaying to the Mössbauer nucleus ${ }^{133} \mathrm{Cs}$ ). ${ }^{131 \mathrm{~m}} \mathrm{Xe}$ is usually ruled out because of its low resolution. ${ }^{129 m} \mathrm{Xe}$ offers the advantage that Mössbauer measurements are performed on the same element as the implanted one, but even here the energy resolution is not very good. ${ }^{133} \mathrm{Cs}$ has excellent resolution, but is only available through the beta decay of ${ }^{133} \mathrm{Xe}$; this may complicate the interpretation of the data in some cases.

${ }^{129 m} \mathrm{Xe}$ and ${ }^{133} \mathrm{Xe}$ have been implanted in Si and Ge at doses around $10^{14} \mathrm{at} / \mathrm{cm}^{2}$ [40] (Fig. 11). In all cases, narrow single lines were obtained, presumably arising from a single well-defined lattice site. Influence of radiation damage was not noticeable.

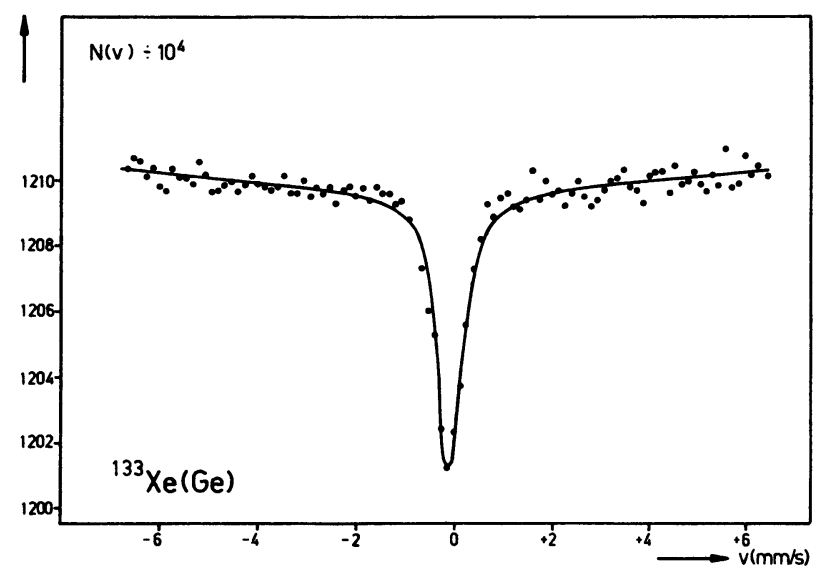

Fig. 11. - Spectrum of ${ }^{133} \mathrm{Xe}$ implanted in Ge at $5 \times 10^{13} \mathrm{at} / \mathrm{cm}^{2}$.

Comparing the isomer shift of the resonance with some Xe compounds known from the literature [41], the position of the ${ }^{129} \mathrm{Xe}$ line was found to coincide almost with the resonance of ${ }^{129} \mathrm{Xe}$ in hydroquinone clathrate. In this compound, $\mathrm{Xe}$ atoms are hold inside hydroquinone cages by weak Van der Waals forces; it was therefore assumed that a similar situation exists in $\mathrm{Si}$ and $\mathrm{Ge}$, which points towards a location of the $\mathrm{Xe}$ at the tetrahedral interstitial site.

Similar conclusions could be drawn from the ${ }^{133} \mathrm{Cs}$ spectra. The isomer shifts in $\mathrm{Si}$ and $\mathrm{Ge}$ were close to the one in Cs metal [42], where Cs is known to have the configuration $5 s^{2} 5 p^{6} 6 s^{1.2}$. Again this is compatible with an interstitial location of $\mathrm{Cs}$ in $\mathrm{Si}$ and $\mathrm{Ge}$, with a supplementary compression effect to account for the excess $6 \mathrm{~s}$ density.

3.4.2 Lattice location of $\mathrm{Xe}$ in diamond. $-{ }^{129 \mathrm{~m}} \mathrm{Xe}$ and ${ }^{133} \mathrm{Xe}$ have been implanted in type IA diamond. In view of their complexity, the spectra markedly differ from the single line patterns previously obtained for the same isotopes in $\mathrm{Si}$ and $\mathrm{Ge}$. A consistent fit of both results is possible if one assumes a strong quadrupole split component together with one or more unsplit lines [43]. In order to test this hypothesis, an integral perturbed angular correlation measurement (IPAC) was carried out on ${ }^{129 m}$ Xe diam, from which the existence of a quadrupole interaction could be unambiguously established [44].

A symmetry breaking due to the presence of vacancies near the impurity is the most probable explanation for the presence of an EFG at the implanted Xe nucleus in diamond. The radius of the neutral $\mathrm{Xe}$ atom $(2.2 \AA)$ or Cs atom $(2.7 \AA)$ is indeed much larger than the nearest neighbour distance at the tetrahedral interstitial site in diamond $(1.5 \AA)$. Therefore, an association of the impurity with vacancies will be energetically favored, much more than in $\mathrm{Si}$ and Ge.

In the case of ${ }^{133} \mathrm{Cs}$, two unsplit components were also required for an adequate fitting of the spectra. The position of both lines

$$
(-3.4 \pm 0.08 \mathrm{~mm} / \mathrm{s}, \quad-1.5 \pm 0.07 \mathrm{~mm} / \mathrm{s})
$$

correspond with a much higher s-electron density at the nucleus than for the quadrupole split component; it even exceeds by an order of magnitude the electron densities which are found for Cs in usual chemical compounds. These lines could therefore be due to highly compressed $\mathrm{Xe}$ atoms situated at regular interstitial sites. Several mechanisms can be involved to increase the $s$-density at the nucleus : direct compression of the $s$-orbitals; delocalization of the p-orbitals, which reduces the shielding of the $s$-electrons; distortion of the inner $s$-wave-functions by overlap with the host ligands. However, no theoretical description of this situation is available at the present moment.

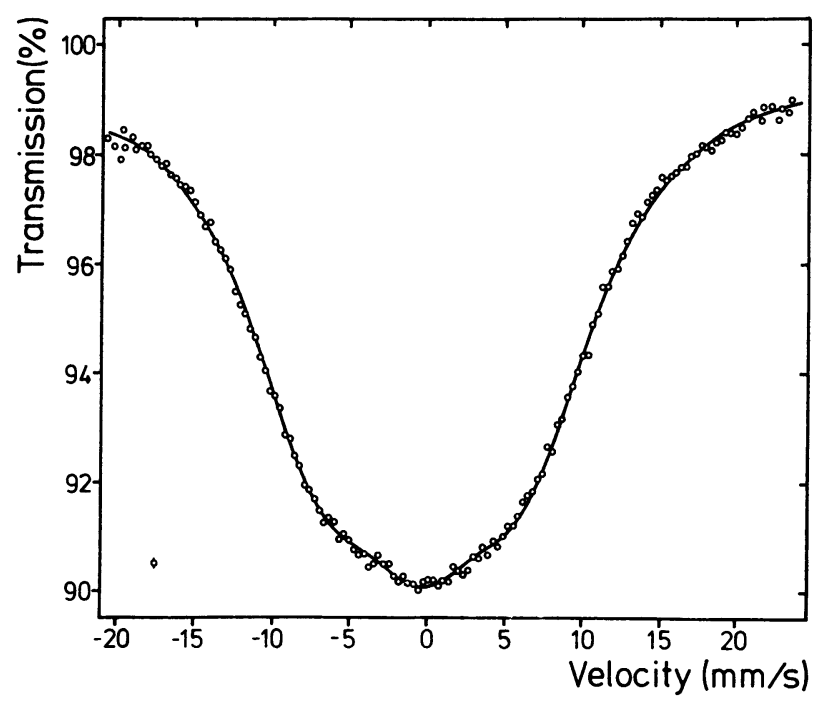

Fig. 12. - Spectrum of ${ }^{129} \mathrm{Xe}$ implanted in diamond. 
For ${ }^{129} \mathrm{Xe}$, the poor resolution of the spectrum does not allow an accurate determination of the isomer shifts. Moreover, the implanted dose of $10^{14} \mathrm{at} / \mathrm{cm}^{2}$ probably exceeds the amorphization limit. It would therefore be hazardous to relate the unsplit resonance to a single well-defined site.

3.4.3 Study of the amorphization process. - It is now well established that, for heavy ion implantations, an amorphous layer builds up at the diamond surface above some critical dose threshold. According to recent experiments of Talmi et al. [45] on Sb implanted in diamond at $300 \mathrm{keV}$, the growth of an amorphous graphite zone occurs between $3 \times 10^{13}$ and $5 \times 10^{14} \mathrm{at} / \mathrm{cm}^{2}$.

Mössbauer spectra of ${ }^{133} \mathrm{Xe}$ implanted in diamond have been recorded for doses between $5 \times 10^{12}$ and $10^{14} \mathrm{at} / \mathrm{cm}^{2}$ [46]. One observes the continuous growth of a resonance line at $-0.20 \pm 0.05 \mathrm{~mm} / \mathrm{s}$

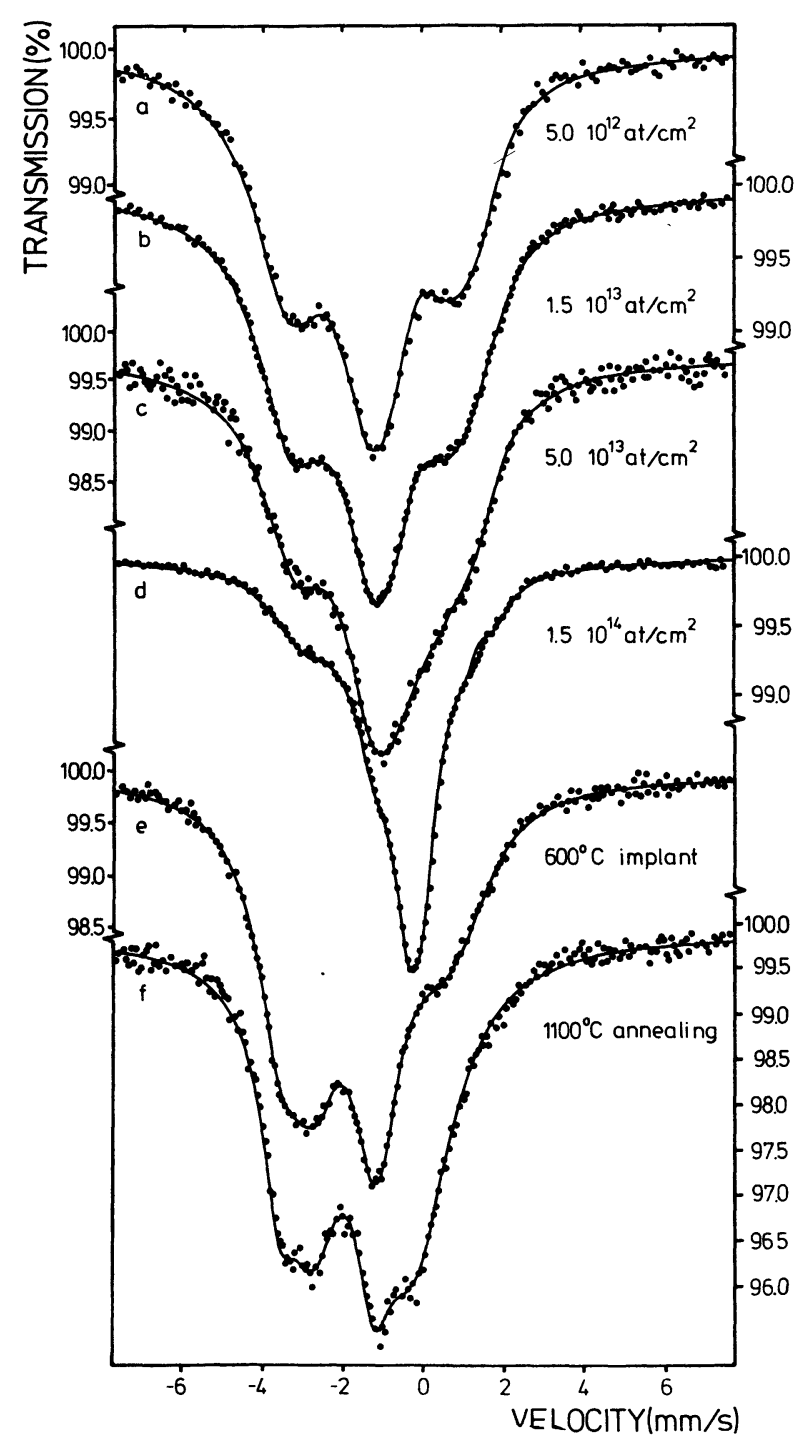

Fig. 13. - Spectra of ${ }^{133} \mathrm{Xe}$ implanted in diamond : a-d dose dependence of the amorphization; $e$ hot implant ; $f$ thermal annealing after implantation. (hereafter called $a$ line), which becomes the dominant component above $10^{14} \mathrm{at} / \mathrm{cm}^{2}$. It is therefore quite natural to identify this line with $\mathrm{Cs}$ atoms in an amorphous lattice surrounding.

Three more experiments can be quoted to support this assignment. First, an implantation of ${ }^{133} \mathrm{Xe}$ in pyrolytic graphite yields a single absorption line at $0.03 \pm 0.05 \mathrm{~mm} / \mathrm{s}$ [47]. Moreover, we have performed a hot implantation of ${ }^{133} \mathrm{Xe}$ at $10^{14} \mathrm{at} / \mathrm{cm}^{2}$ and $600^{\circ} \mathrm{C}$; we also did a room temperature implantation at the same dose, followed by thermal annealing in vacuo $\left(\leqslant 2 \times 10^{-6}\right.$ torr) at $1100^{\circ} \mathrm{C}$. In both cases, the intensity of the $a$ line has been greatly reduced (see Fig. 13). Under similar conditions, one observes by EPR a decrease of the isotropic $g=2$ signal, which is related to the amorphization of the implanted volume. We thus conclude that the annealing of the amorphous layer can also be observed by Mössbauer spectroscopy.

After heat treatment, a new line appears in the spectrum at $-2.73 \pm 0.07 \mathrm{~mm} / \mathrm{s}$. The origin of this line is still not understood.

4. Conclusion. - The survey we have presented was not aimed to be exhaustive. In fact, we have restricted our interest to implantations in type-IV semiconductors and we have omitted several nuclides $\left.{ }^{\left({ }^{125} \mathrm{Te},\right.}{ }^{83} \mathrm{Kr},{ }^{73} \mathrm{Ge} \ldots\right)$ on which interesting work is still in progress. In many respects, however, the study of lattice defects by Mössbauer Spectroscopy is still in its infant age. Since we have to draw tentative conclusions, we would like to distinguish between several aspects of this topic :

1) Lattice locations : this is the primary information provided by the Mössbauer spectrum. Although it is nearly always possible to deduce something about lattice location of impurities, a site assignment is rarely as straightforward as e.g. by channeling measurements. On the other hand, Mössbauer spectroscopy does not suffer from the many limitations which preclude the use of channeling techniques (polycrystalline samples, amorphous materials, low concentration of impurities, etc.).

2) Amorphization : some Mössbauer nuclides provide excellent probes for lattice amorphization and usually more complete information is obtained than by other methods.

3) Isolated defect studies : little work has been done up to now in the field of defect formation and migration. However, several Mössbauer impurities have been found to interact with specific defect types and a lot of information can probably be gained from a more intensive study of these favorable cases. Here again, complete identification of the defects is usually not possible from the Mössbauer spectrum alone. It would be especially interesting to combine this method with other microscopic techniques such as optical spectroscopy and EPR. 
Finally, we should like to emphasize that Mössbauer Spectroscopy on semiconductors has mostly been performed by Mossbauer specialists, whereas significant progress may be expected if it could draw more attention from the world of semiconductor specialists.

Acknowledgments. - The authors wish to thank the Leuven Implantation team for the sample prepa- rations which made much of this work possible. They also thank Dr. J. Odeurs and Dr. H. Pattyn for making some results available prior to publication.

Prof. J. D'Olieslager is gratefully acknowledged for his help with the laser set-ups.

The Reactor Center of Mol (S.C.K.) is acknowledged for the irradiation facilities.

This work has been financially supported by the I.I.K.W.

\section{References}

[1] Many reference books are available on the Mössbauer Effect. See f. ex.

L'effet Mössbauer et ses applications C. Janot (Masson \& Cie, Paris 1972).

Mössbauer Spectroscopy N. N. Greenwood and T. C. Gibb (Chapman and Hall, London 1971).

Principles of Mössbauer Spectroscopy T. C. Gibb (Chapman and Hall, London 1976).

Mössbauer Isomer Shifts ed. G. K. Shenoy and F. E. Wagner (North-Holland, Amsterdam 1978).

[2] De WaArd, H., DrentJe, S. A., Phys. Lett. 20 (1966) 38.

[3] De Waard, H., Drentje, S. A., Proc. Roy. Soc. A 311 (1969) 139.

[4] De Waard, H., Reintsema, S. R., Phys. Lett. 29A (1969) 290.

[5] De WAARD, H., in Mössbauer Spectroscopy and its applications (IAEA, Vienna 1972) p. 123.

[6] Odeurs, J., Coussement, R., Pattyn, H., Hyp. Int. 4 (1977) 469.

[7] Odeurs, J., Coussement, R., Pattyn, H., Rad. Eff. 39 (1978) 11.

[8] Van Rossum, M., Langouche, G., Pattyn, H., Dumont, G., Odeurs, J., Meykens, A., Boolchand, P., Coussement, R., J. Physique 35 (1974) C6-301.

[9] Odeurs, J., Pattyn, H., Verbiest, E., to be published.

[10] Pattyn, H., Coussement, R., de Bruyn, J., Odeurs, J., van Rossum, M., J. Nucl. Materials 69 \& 70 (1978) 764.

[11] De WaArd, H., Feldman, L. C., in Applications of Ion Beams to metals ed. Picreaux, Eernisse, Vook (Plenum Press, New York 1974) p. 317.

[12] Mansel, W., Vogl, G., Koch, W., Phys. Rev. Lett. 31 (1973) 359.

[13] VoGL, G., J. Physique 35 (1974) C6-165.

[14] Vogl, G., Mansel, W., Vogl, W., J. Phys. F4 (1974) 2321.

[15] VoGL, G., Hyp. Int. 2 (1976) 151.

[16] Reintsema, S. R., Verbiest, E., Odeurs, J., Pattyn, H., to be published in J. Phys. F. (1979)

[17] Odeurs, J., Pattyn, H., Verbiest, E., Coussement, R., ReintSEMA, S. R., BRICE, D. K., to be published.

[18] Sawicka, B. D., Sawicki, J. A., in "Proceedings of the International Conference on Mössbauer Spectroscopy " ed. D. Barb, D. Tarina (National Centre for Physics, Bucharest 1977).

[19] Weyer, G., Deutch, B. I., Nylandsted Larsen, A., Nielsen, H. L., J. Physique 35 (1974) C6-297.

[20] Weyer, G., Nylandsted Larsen, A., Deutch, B. I., ANDerSEN, J. V., ANTONCIK, E., Hyp. Int. 1 (1975) 93.

[21] Weyer, G., Nylandsted Larsen, A., Deutch, B. I., AntonCIK, E., LOFT Nielsen, H., in Radiation Effects in Semiconductors, 1976 ed. N. B. Urli and J. W. Corbett (Conference Series $\mathrm{n}^{\circ}$ 31, Institute of Physics, London 1977) p. 491.

[22] Weyer, G., Deutch, B. I., Nylandsted LaRsen, A., Loft NiELSEN, H. L., Hyp. Int. 2 (1976) 370.

[23] Weyer, G., Andersen, J. V., Deutch, B. I., Golovchenko, J. A., Nylandsted Larsen, A., Rad. Eff. 24 (1975) 117.

[24] AntoncIK, E., in Lattice defects in Semiconductors, 1974 ed. A. Seeger (Conference Series nr. 23, The Institute of Physics, London 1975) p. 565.

[25] Holm, N. E., Nylandsted Larsen, A., Deutch, B. I., Weyer, G., paper presented at the International Conference on defects and radiation effects in semi-conductors, Nice 1978.

[26] Matsui, K., Hasiguti, R. R., Shoji, T., Ohkawa, A., in Lattice defects in Semiconductors, 1974 ed. A. Seeger (Conference Series nr. 23, The Institute of Physics, London 1975), p. 572.

[27] Hafemeister, D. W., De WaArd, H., Phys. Rev. B7 (1973) 3014.

[28] De WaArd, H., Bukshpan, S., Kemerink, G. J., Hyp. Int. 5 (1977) 45.

[29] De Bruyn, J., Langouche, G., De Potter, M., Van Rossum, M., Coussement, R., to be published in Physics Letters.

[30] Foti, G., Campisano, S. U., Rimini, E., Vitali, G., J. Appl. Phys. 49 (1978) 2569.

[31] Roberts, L. D., Page, C., Dale, J. H., Josephson, W. D., B.A.P.S. 24 (1979) 427.

[32] Norem, P. C., WertheIm, G. K., in The Mössbauer Effect ed. D. M. J. Compton and A. M. Schoen (J. Wiley \& Sons, New York 1962) p. 294.

[33] Latshaw, G. L., thesis unpublished (1971).

[34] De S. Barros, F., Hafemeister, D., Viccaro, P. J., J. Chem. Phys. 52 (1970) 2865.

[35] Weyer, G., Grebe, G., Ketrschau, A., Deutch, B. I., Nylandsted Larsen, A., Holm, O., J. Physique 37 (1976) C6-893.

[36] Weyer, G., Ketrschau, A., Grebe, G., Schröter, W., BerGHOLz, W., Phys. Stat. Sol. (a) 51 (1979) 459.

[37] Langouche, G., Dezsi, I., Van Rossum, M., De Bruyn, J., Coussement, R., Phys. Stat. Sol. (b) 89 (1978) K 17.

[38] Langouche, G., Dezsi, I., de Bruyn, J., van Rossum, M., Coussement, R., J. Physique 40 (1979) C2-547 and to be published.

[39] Langouche, G., de Potter, M., De Bruyn, J., van Rossum, M., Coussement, R., to be published in J. Physique.

[40] Van Rossum, M., De Bruyn, J., Langouche, G., Coussement, R., J. Physique 37 (1976) C6-889.

[41] Perlow, G. J., in Chemical Applications of Mössbauer Spectroscopy ed. V. I. Goldanskii and R. H. Herber (Academic Press, New York 1968) p. 378.

[42] Boyle, A. J. F., Perlow, G. J., Phys. Rev. 151 (1966) 211.

[43] Van Rossum, M., de Bruyn, J., Langouche, G., Rots, M., Ooms, H., Claes, J., Namavar, F., Coussement, R., Hyp. Int. 4 (1978) 727.

[45] Talmi, A., Beserman, R., Tajcher, M., Braunstein, G., KALISH, R., paper presented at the "International Conference on defects and radiation effects in semiconductors " Nice (1978).

[46] Van Rossum, M., de Bruyn, J., de Potter, M., Langouche, G., Coussement, R., to be published.

[47] Dezsi, I., Coussement, R., Langouche, G., Pattyn, H., Reintsema, S. R., van Rossum, M., De Bruyn, J., $J$. Physique 40 (1979) C2-573. 